\title{
Social significance of trunk use in captive Asian elephants
}

$\operatorname{AUTHOR}(S)$ :

Yasui, Saki; Idani, Gen'ichi

CITATION:

Yasui, Saki ...[et al]. Social significance of trunk use in captive Asian elephants. Ethology Ecology \& Evolution 2017, 29(4): 330-350

ISSUE DATE:

2017-07-04

URL:

http://hdl.handle.net/2433/228270

\section{RIGHT:}

This is an Accepted Manuscript of an article published by Taylor \& Francis in 'Ethology Ecology \& Evolution' on 2017, available online: https://www.tandfonline.com/10.1080/03949370.2016.1179684 .; The full-text file will be made open to the public on 04 July 2018 in accordance with publisher's 'Terms and Conditions for Self-Archiving'.; この論文は出版社 版でありません。引用の際には出版社版をご確認ご利用ください。; This is not the published version. Please cite only the published version. 
1 Social significance of trunk use in captive Asian elephants

2

3 SAKI YASUI ${ }^{1, *}$ and GEN'ICHI IDANI ${ }^{2}$

$4{ }^{1}$ Kyoto City Zoo, Okazaki Koen, Okazaki Houshojicho, Sakyo-Ku, Kyoto city, Kyoto,

5 606-8333, Japan

$6{ }^{2}$ Wildlife Research Centre,

7 Wildlife Research Centre, Kyoto University, 2-24 Tanaka-Sekiden-cho, Sakyo-Ku,

8 Kyoto, 606-8203, Japan

9

$10{ }^{*}$ Corresponding author: Saki Yasui, Kyoto City Zoo, Okazaki Koen, Okazaki

11 Houshojicho, Sakyo-Ku, Kyoto city, Kyoto 606-8333, Japan (E-mail: s2a1k9i@gmail.com).

14 Running head: Social significance of trunk use 
17 in several mammalian species. Touching with the tip of the trunk is a common social behaviour among Asian elephants (Elephas maximus). This is considered an affiliative behaviour; however, few studies have investigated it in detail. Therefore, this study aimed to determine whether this is an affiliative behaviour and whether it has other functions. We directly observed a group of captive female Asian elephants in Thailand. We found that the elephants usually touched each other with their trunks shaped in a U (U-type) or S (S-type) shape. The S-type shape was observed mainly when the elephants touched the lips of other elephants; however, this behaviour was occasionally observed in agonistic or play contexts, where it appeared to be a threat or dominant behaviour, particularly within adults. In contrast, the U-type shape was more frequently observed when the elephants were disturbed, where it appeared as a gesture for reassurance. We found that the U-type touch on the genitals may be used for interacting with neonates. Therefore, we suggest that despite the $\mathrm{S}$-type touch having a tactile component, it may be a rare behaviour in Asian elephants that is similar to visual threat displays in other mammals. However, the U-type touch is similar to social grooming behaviour in primates or flipper rubbing in dolphins and can be used as an indicator of 
34 affiliative relationships. Asian elephants change the shape of their trunk while

35 touching others depending on their motivation and the situation, thereby

36 demonstrating that the nuances of trunk use can assist in understanding the social

37 relationships between individuals.

38

39 KEY WORDS: Asian elephant, touch with trunk, function, affiliative, aggressive. 


\section{INTRODUCTION}

In various animal species, social relationships are regulated by tactile

behaviours. Social grooming is one such tactile behaviour that has been frequently

studied in various mammalian species (Spruijt et al. 1992). In most species, the

primary function of grooming is to maintain healthy skin by removing parasites

45 (Spruijt et al. 1992). However, social grooming has several additional functions, such as reconciliation and consolation following an aggressive interaction

47 (Nakamura \& Sakai 2013) and the maintenance of social bonds (Dunbar 1991, 2010; Nakamura \& Sakai 2013). Thus, it is an indicator of affiliative relationships

(McCowan et al. 2008; Kasper \& Voelkl 2009). Dolphins exhibit a tactile behaviour termed flipper rubbing, which has functions similar to those of social grooming in primates (Sakai et al. 2006; Tamaki et al. 2006). Thus, tactile interactions are utilized for various purposes and are important for establishing and maintaining social relationships. Elephant societies exhibit complexity similar to that of primate and cetacean societies (Poole \& Moss 2008). The societies of both Asian (Elephas maximus) and African (Loxodonta spp.) elephants are centred on maternal groups. 
the males leave the group when they become sexually mature. However, the family

African elephants have revealed that they have a hierarchical social structure

(Wittemyer et al. 2005), whereas Asian elephants tend to form smaller groups with

a looser association (de Silva et al. 2011). Asian elephants use vocal, seismic (Payne

(Rasmussen 1999) communication to maintain their complex social structure.

Tactile behaviour is an important and prominent behaviour between them (Vidya

\& Sukumar 2005); however, few studies have investigated this behaviour to date.

(Gadgil \& Nair 1984; Makecha et al. 2012), which serves not only as a form of tactile communication but also as a form of chemical communication (Garaï 1992;

Makecha et al. 2012). Asian elephants have an excellent sense of smell and receive chemical information by touching body orifices or glands (Rasmussen \&

73 Krishnamurthy 2000). Some studies have shown that elephants touch the genitals and interdigital glands to assess the oestrus state of females (Slade et al. 2003; 
with the trunk is an affiliative behaviour (Garaï 1992; Makecha et al. 2012). For example, touching the lips or mouth of another individual with the trunk is associated with investigation of food, reassurance, affirmation of affiliative relationships and individual recognition (Garaï 1992; Langbauer 2000; Sukumar 2003; Plotnik \& de Waal 2014). In addition, touching the genitals of another individual provides reassurance or an exchange of information regarding health or reproductive state (Garaï 1992; Sukumar 2003; Kurt \& Garaï 2006). However, to date, only a few studies have systematically investigated the precise function of the various types of elephant trunk touches.

Elephant trunks have a function similar to that of human and primate hands (Onodera \& Hicks 1999; Martin \& Niemitz 2003). Elephants use their trunks to feed and communicate in a manner similar to how primates use their hands for the same purposes. Elephant trunks are flexible; therefore, elephants can change their trunk shape depending on their requirements, such as for grabbing or reaching out. However, both Asian and African elephants can communicate with each other by changing their trunk shape, just as humans can change their hand shape to convey various intentions (McNeill 1992; Moss et al. 2011). African elephants entwine their trunks with one another as a greeting or 
94 during play (Moss et al. 2011). Garaï (1992, p. 14) reported that Asian elephants sometimes touched the mouths of other elephants using a complicated twisting of the trunk, which she speculated is used to prevent aggressive behaviour from escalating. Therefore, it is possible that elephants change their trunk shape to convey different intentions to the recipients. Deciphering complex behaviours, such as the form and function of elephant trunk use, will provide us with a better understanding of the social relationships among Asian elephants.

102 elephant trunk touching by recording the trunk shape and any associated behaviours. In the present report, we examined the relationship between the types

104 of trunk touch and the proximity between individuals, which is frequently used as an index of affiliative relationships among primates and elephants (Garaï 1992; Schel et al. 2013). We also investigated the behavioural context around trunk touching (play and aggression) to understand the nature of this type of tactile communication among Asian elephants. 
113 Ban Ta Klang Elephant Village, Surin Province, Thailand (15¹5'59.7"N,

$114103^{\circ} 29^{\prime} 48.3^{\prime \prime} \mathrm{E}$ ), which is managed by the Zoological Park Organization and the

115 Surin Provincial Administration Organization. This village is home to the Guay

116 tribe, who are known for their skills in caring, training and working with

117 elephants. This region experiences three seasons: summer (February-April), rainy

118 (May-October) and winter (November-January) (Polthanee \& Promkhambut

119 2014). Approximately 200 elephants have been registered at the Centre by their

120 mahouts, Approximately 40 elephants work at elephant shows or provide rides for

121 tourists, whereas others work in volunteer programmes (e.g. allowing visitors to

122 experience the lifestyle of a mahout). The elephants at the Centre also participate

123 in ceremonies or parades in other regions of Thailand. When the elephants have no

124 work, they are chained in front of the mahout's house or sheltered in the village

125 and are taken on walks for bathing a few times each day.

Research periods and subjects 
130 the group of elephants that was involved in the Surin Project volunteer programme,

131 which was started in 2009 by the Save Elephant Foundation. This group usually

132 included 10-13 elephants. During our study period, some elephants left or newly

133 joined the group. We observed a total of 17 elephants (16 females and one male;

134 Table 1).

All elephants under observation were born in captivity, but their life

136 histories before joining the project differed. Some elephants were used for working

137 in shows, whereas others were used for street begging (walking the city streets to

138 obtain money from tourists by providing them the experience of feeding elephants,

139 etc.). In addition, some elephants were cared for by only one mahout or his family

140 members for their entire lives, whereas others were cared for by different mahouts.

141 We identified each individual elephant by their body size or body

142 characteristics (e.g. ear or tail shape and pink pigmentation on their ears and

143 trunks). We categorised the elephants into four age classes: neonate (birth to 2

144 years), juvenile (3-10 years), subadult (11-15 years) and adult (> 15 years). The

145 neonates were usually tied to their mother with a rope (approximately $2 \mathrm{~m}$ ) around

146 their necks. 
150 an enclosure in the village for $3-6 \mathrm{hr}$ per day, following the weekly schedule of the

151 Surin Project. The mahouts usually stayed around their elephants and

152 occasionally interacted with their elephants during activities. The volunteers and

153 staff of the Surin Project also walked with the elephants, although they always

154 maintained a greater distance between themselves and the elephants than the

155 mahouts and did not interact with the elephants. During their walks, the

156 elephants occasionally stopped walking to eat bark in the forest or the sugar cane

157 that had been scattered for them in advance. During their time at the enclosure,

158 the volunteers and staff did not stay in the enclosure, whereas the mahouts

159 remained near their own elephants or at the shelter in the enclosure. All

160 observations were conducted by S. Yasui, who also conducted the preliminary

161 observations of the same study group from December 2011 to March 2012. All

162 elephants showed little interest in the observer during the study periods,

163 indicating that the observer had almost no influence on their behaviours. 
166 the enclosure together except when they showed health problems or were required

167 to work elsewhere. Focal animal sampling (Altmann 1974) was conducted on one

168 target animal during each activity, using a total of 10 females. All social behaviour

169 relating to the focal animal were recorded continuously (Martin \& Bateson 1993)

170 using an IC digital voice recorder (SONY ICD-UX523) and a video camera (SONY

171 HDR-550V), and the names and postures of the actor and recipient were also noted.

172 All observation data on the elephants during both study periods are provided in

173 Table 1. The total observation time was $271.9 \mathrm{hr}$. Each subject was observed 17-23

174 times (average $20.2 \pm 1.89$ ) for an average duration of $1.34 \pm 0.58 \mathrm{hr}$. The distance

175 between the target animal and the observer was 2-30 m. All subjects were under

176 the authority of their mahouts. At few instances, the mahouts attempted to stop

177 interactions, particularly severe aggressive interactions, between the elephants

178 using vocal commands or physical contact. All observations were made following

179 the guidelines on the ethics of animal studies of the Wildlife Research Centre of

180 Kyoto University.

181

Definitions and terminology 
184 tip of the elephant trunk. It has been shown that elephants exhibit social

185 behaviours more frequently when they become excited (Garaï 1992; Plotnik \& de

186 Waal 2014). Therefore, we defined an excited situation as one in which the focal

187 animal made any vocalisation combined with excited postures (head or tail raised

188 and ears extended). This excited situation ended when the subject returned to the

189 normal posture (de Silva et al. 2011; Moss et al. 2011). We used the modified

190 versions of ethograms presented in previous studies for our observations (Table 2;

191 Olson 2004; Moss et al. 2011).

192

Data analysis

Initially, we determined whether there were any differences in the observed

number of times elephants touched different body parts and whether there were

any age-related differences in the number of times elephants touched or received

touches. We examined differences in touch frequencies between individuals and

pairs of elephants. To calculate the touch frequency for each individual, the

199 observed number of times that the focal animal touched or received touches was 
$202 \mathrm{O}_{\mathrm{AB}-\mathrm{A}}$ indicates the number of times that $\mathrm{A}$ touched $\mathrm{B}$ when $\mathrm{A}$ was the focal animal,

$203 \mathrm{O}_{\mathrm{AB}-\mathrm{B}}$ indicates the number of times that $\mathrm{A}$ touched $\mathrm{B}$ when $\mathrm{B}$ was the focal animal,

$204 \mathrm{~T}_{\mathrm{AB}}$ indicates the time during which both $\mathrm{A}$ and $\mathrm{B}$ were in the study group with $\mathrm{A}$

205 as the focal animal and $\mathrm{T}_{\mathrm{BA}}$ indicates the same measurement with $\mathrm{B}$ as the focal

206 animal.

We also examined whether touches were correlated with the proximity

208 index for each pairs of elephants, which was calculated using the formula: $\left(\mathrm{P}_{\mathrm{AB}}+\right.$

$\left.209 \mathrm{P}_{\mathrm{BA}}\right) /\left(\mathrm{T}_{\mathrm{AB}}+\mathrm{T}_{\mathrm{BA}}\right)$, where $\mathrm{P}_{\mathrm{AB}}$ indicates the time when $\mathrm{A}$ and $\mathrm{B}$ were in proximity to

210 each other with $\mathrm{A}$ as the focal animal and $\mathrm{P}_{\mathrm{BA}}$ indicates the same measurement

211 with B as the focal animal. In this context, proximity refers to when either of the

212 two individuals could touch the body of the other. Four individuals (Thong deng,

213 Soi thong, Tuk or Kham koon) were excluded from the present analysis as they

214 stayed in the same group for $<10 \mathrm{hr}$ during each focal observation period. In

215 addition, we did not include proximity data between Kaem sean and Nopa gao as

216 they were tied to each other.

We then examined whether the frequency of touching increased when the elephants were excited. In the present analysis, we distinguished between excited

219 situations in which the mahout interacted with the elephants, for example, using 
220 vocal commands or physical contact to calm their elephants (excited with mahouts)

221 and those in which there was no interaction between the mahout and the elephant

222 (excited). We also distinguished between normal situations in which the mahouts

223 held the ears of their elephants to direct them (normal with mahouts) and those

224 that did not require the ears to be held (normal). Thus, we compared the frequency

225 of touches between four situations: normal, normal with mahouts, excited and

226 excited with mahouts. In addition, we categorised the excited situations according

227 to the perceived cause of the excitement (i.e. disturbance and play; see Table S1 of

228 supplemental material for definitions) and compared the frequency of touches

229 between the normal situations and each of these categories. We examined whether

230 both the actor and recipient of the touches were excited or only one of these was

excited.

To interpret the social context of the touches, we investigated the social

behaviours that occurred just before and after the touch. We also investigated the

relationship between the context of the touches and pair types: with or without

adults, subadults and 'young' (juveniles and neonates). Here, each category

indicates that one or both individuals of the pair belonged to that age category, for 
238 We also investigated whether the actor exhibited a threat posture during the 239 touch.

We conducted all analyses using generalised linear mixed-effect models

241 [GLMER function using the lme4 package in R software (Version 2.15.3)]. GLMER

242 fits the model using the maximum likelihood method. The best model was then

243 selected from all possible models with or without each explanatory variable based

244 on the Akaike information criterion (AIC, Akaike 1974). The model with the lowest

245 AIC value was chosen as the best model. Multiple pair-wise comparisons were then

246 performed using Tukey's method with the GLHT function in the multcomp package.

247 To examine the frequency at which elephants touched different body parts, we

248 included the observed times of touch as a response variable, body part as an

249 explanatory variable and log (focal time) as an offset. We also included animal

250 identification (ID) as a random effect to avoid pseudo-replication (Hurlbert 1984).

251 To analyse the effect of age on touch frequencies, we included the observed number

252 of touches as the response variable, age class as an explanatory variable, log (focal time) as an offset and animal ID as a random effect. We tested the relationship between each touch and the proximity index by including the observed number of touches as the response variable, the proximity index as an explanatory variable, 
$256 \log$ (time when the two individuals in each pair remained in the study group) as an

257 offset and pair ID as a random effect. To investigate the effect of excitement on

258 touch frequency, we included the observed number of touches as the response

259 variable, the situation (normal with mahout, normal, excited with mahout or

260 excited) as an explanatory variable, log (focal time) as an offset and animal ID as a

261 random effect. The Poisson distribution and a log link function were used for these

262 analyses.

We categorised all social behaviours into one of the four groups: movement,

264 touch/smell, aggression or play (see Table 2). To compare the effect of social

265 behaviours on touch frequencies, we included the occurrence of a social behaviour

$266(1=$ yes or $0=$ no $)$ as the response variable, the touch type as an explanatory

267 variable, and pair ID as a random effect. We also investigated the effect of pair

268 type (with or without adults, subadults and young) on social behaviour by

269 including the occurrence of a social behaviour $(1=$ yes or $0=$ no $)$ as the response

270 variable, the pair type as an explanatory variable, and pair ID as a random effect.

271 We also included command (whether the mahouts used a vocal command to stop

272 interactions following the touch as an explanatory variable to investigate the effect

273 of interactions with the mahouts. The binomial distribution and a logit link 
274 function were used for these analyses.

276 types by including the observed number of U-type lip touches as the response

277 variable, the observed number of U-type genital touches and pair type (with or

278 without adults, subadults, juveniles and neonates) as explanatory variables, and

279 pair ID as a random effect. The Poisson distribution and a log link function were 280 used for this analysis.

\section{RESULTS}

Overview

In most cases, the 10 female elephants touched the body parts of other

elephants with their trunks in a U-shape (U-type, Fig. 1a), but occasionally with

their trunks in an S-shape (S-type, Fig. 1b). All elephants performed or received

both U-type and S-type touches during the study. The elephants performed S-type

when touching others' genitals. 
292 elephants touched around the mouth (lips) or inside the mouth (mouth).

293 Recipients opened their mouths during mouth touches whereas they usually closed

294 their mouth during lip touches. All subjects performed touches to all body parts,

295 despite the varying body size of the focal animals. The elephants touched the lips

296 and genitals of other elephants more frequently than any other parts of the body

297 (Fig. 2, lips vs all other body parts, $P<0.01$; genitals vs all other body parts, $P<$

298 0.01). Therefore, we specifically focused on these two touches. In 83 of 193 S-type

299 touches, the elephants performed a U-type touch either before or after the S-type

300 touch at the same distance from the recipient. Thus, it appeared as natural and

301 easy for the elephants to touch with their trunks in the U-type shape; however,

302 they also sometimes touched with their trunks in the S-type shape. The observed

303 number of each touch type during each focal period is shown in Table 3. As

304 observed, individuals that performed or received U-type touches frequently did not

305 typically perform or receive S-type touches frequently.

306

Differences between pairs in touch frequency are shown in Table 4. Of the

307 top $10 \%$ of pairs that performed U-type lip touches, five also ranked in the top $10 \%$

308 for U-type genital touches. In contrast, of the top $10 \%$ of pairs that performed

309 S-type lip touches, only one pair ranked in the top $10 \%$ for U-type genital touches, 
310 and no pair ranked in the top $10 \%$ for U-type lip touches. In Table 4 , the

311 individuals are arranged according to age (oldest to youngest). For all touch types,

312 younger individuals touched older individuals at an almost identical frequency to

313 older individuals touching younger individuals in the top $10 \%$ of pairs. The

314 subadults received S-type lip touches more frequently than the adults $(N=10$;

315 adults vs subadults: coefficient $=-1.41 \pm 0.57, z=-2.47, P=0.04$; adults vs

316 juveniles: coefficient $=-0.76 \pm 0.59, z=-1.29, P=0.40$; subadults vs juveniles:

317 coefficient $=0.66 \pm 0.0 .58, z=1.13, P=0.50)$. However, there was no relationship

318 between age class and the frequency of receiving U-type lip and U-type genital

319 touches). One mother (Kaem sean) only gave U-type lip touches 0.07 times/hr and

320 U-type genital touches 0.14 times/hr to her son, Nopa gao, despite them usually being

321 attached to each other with a rope. Kanoon performed the highest frequency of U-type touches to Nopa gao (U-type lip: 0.99 times/hr; U-type genital: 2.55 times/hr). Kaem sean did not give any S-type lip touches to her son.

Relationship between touches and proximity 
328 behaviours between pairs whose proximity index was $>0.15$. Therefore, we used

329 the data from all 74 pairs in our analyses. The models for U-type lip touches and

330 U-type genital touches, including the proximity index, were chosen as the best

331 models (Fig. 3, U-type lip: coefficient $=7.84 \pm 1.16$; U-type genital: coefficient $=$

$3328.47 \pm 0.87)$. In contrast, the model that included the proximity index was not

333 selected as the best model for S-type touches. Therefore, proximity is not

334 necessarily related to the frequency of S-type touches.

335

336

Relationship between touches and excitement

337

For the 10 focal animals, frequencies of all touch types were relative to the

338 situation (Table 5a). Elephants performed U-type lip and U-type genital touches

339 more frequently when they were excited (excited and excited with mahouts) than

340 under normal situations (normal and normal with mahouts), with a significant

341 difference between normal and excited. The frequency of U-type genital touches

342 was not related to the type of situation either with or without interaction with the

343 mahouts, and the frequency of S-type lip touches did not significantly differ

344 between normal and excited situations which involved no interaction with the mahouts. 
In 347 of 635 excited events, we could identify the cause of excitement,

347 which included disturbance, play and interaction by the mahouts. The definitions

348 of each of these are provided in Table $\mathrm{S} 1$ (supplemental material). In our analyses,

349 we examined the touch frequencies in each of these situations by including normal,

350 disturbance and play events that were observed for a sufficient time and were

351 unrelated to human interaction, as well as normal, disturbance and play situations

352 involving interaction with mahouts. The model comprising these detailed

353 situations was selected as the best model for all touch types (Table 5b). U-type lip

354 and genital touches were observed significantly more frequently during

355 disturbance and play than during normal situations $(P<0.01)$. In addition, S-type

356 lip touches were observed more frequently during disturbance and play involving

357 interaction no interaction with the mahouts than during normal situations

358 involving interaction with the mahouts $(P<0.05)$, whereas was no significant

359 difference existed among disturbance, play and normal situations involving no

360 interactions with the mahouts.

361

During disturbances, both the actor and recipient were excited for $49.99 \%$

$362 \pm 21.22 \%$ of U-type lip touches and $45.85 \% \pm 19.48 \%$ of U-type genital touches.

363 During play, both the actor and recipient were excited for $71.43 \% \pm 45.18 \%(N=10)$ 
of U-type lip touches and $44.27 \% \pm 39.80 \%$ of U-type genital touches.

\section{Behavioural context before and after touches}

play behaviour observed before or after touches (Fig. 4, U-type lip: $N=1444$; S-type

lip: $N=193$; U-type genital: $N=807$ ). When analysing the proportion of touches in

which aggressive behaviour occurred before the touches, the model that included

touch type was selected as the best model. A higher proportion of aggressive

behaviour occurred before S-type lip touches than before U-type lip and genital

0.01; U-type lip vs U-type genital: coefficient $=0.11 \pm 1.24, z=0.09, P=0.99$;

U-type lip vs S-type lip: coefficient $=-3.54 \pm 0.79, z=-4.45, P<0.01)$. 
382 S-type lip: coefficient $=-2.27 \pm 0.25)$. The results of the analyses of all social

383 behaviours before and after touches are shown in Table S2 (supplemental 384 material).

S-type lip touches than during U-type lip and genital touches (S-type lip vs U-type coefficient $=0.09 \pm 0.17, z=0.52, P=0.86$; U-type lip vs S-type lip: coefficient $=-$ excluded from this analysis. Play behaviour occurred before S-type lip touches at a individuals (Fig. 5, with young: $N=111$, coefficient $=2.46 \pm 1.95$, without young: $N$

$394=82$, coefficient $=-4.39 \pm 1.01)$ but at a lower frequency in pairs with adults than in 395 those without adults (with adults: $N=91$, coefficient $=-4.50 \pm 1.01$; without adults: $N=102$, coefficient $=2.66 \pm 1.05$ ). There was no relationship between the occurrence of subadults in a pair (with subadults: $N=131$; without subadults: $N=$ of play behaviour after S-type lip touches were neither related to any pair type nor 
to vocal commands from the mahouts.

was not related to any pair type. The frequency of aggressive behaviour after

S-type lip touches was also unrelated to vocal commands from the mahouts.

As shown in Fig. 6, pairs that included neonates had a tendency to perform

fewer U-type lip touches and more U-type genital touches than pairs without neonates. The model that included U-type genital touches and pair type with neonates was selected as the best model (U-type genital: coefficient $=0.05 \pm 0.01$; pair type with neonates: $N=30$, coefficient $=-0.80 \pm 0.39$; pair type without neonates: $N=84$, coefficient $=1.71 \pm 0.43)$. U-type genital touches were observed in 14 of 30 pairs with neonates. In $70.80 \% \pm 7.81 \%$ of these touches, it was the elders (those older than neonates) who touched the genitals of the neonates. 
418 analyse the functions of different touch types in elephants. and pairs; therefore, we included animal ID or pair ID as a random factor in all analyses. Only one of the analysed variables was affected by age: the subadults received S-type lip touches more frequently than the adults. This could be related to the time when the subadults had been in the study group, as will be discussed later. behaviours by investigating the relationship between these touches and the proximity index. In our study group, the proximity indices were not positively correlated with aggressive behaviours. In addition, pairs with high proximity indices did not exhibit any aggressive behaviour. These findings confirmed that the proximity index was an appropriate affiliative index in our study group. Further, we found that the frequencies of U-type lip and genital touches were positively correlated with the proximity index, whereas the frequency of S-type lip touches was not, which may suggest that the U-type lip and genital touches are affiliative. 
436 Slade-Cain et al. 2008; Makecha et al. 2012). Similarly, in African elephants,

437 studies have described mouth and genital touches as types of greeting behaviours

438 (Moss 1988; Moss et al. 2011).

439

Next, we examined whether the touches were used more frequently when

440 the elephants were excited. U-type lip and genital touches were observed more

441 frequently during excited situations than during normal situations and were

442 frequently used when elephants became excited because of disturbance.

443 Furthermore, for many of the U-type touches, both the actor and the recipient were

444 excited. These findings might suggest that the elephants touch the lips or genitals

445 of other individuals with U-shaped trunks to reassure others and themselves

446 during disturbances. Similarly, in a captive group of four Asian elephants, Garai

447 (1992) reported that lip and genital touches occurred more frequently during

448 arousal than during non-arousal. Furthermore, Plotnik and de Waal (2014) showed

449 that captive Asian elephants frequently touched the genitals and mouths of other

450 individuals following stressful situations. Our results supported these patterns

451 and also showed that the trunk touch type varied between circumstances.

452 Therefore, as with humans and non-human primates (Hertenstein et al. 2006),

453 physical contact between elephants appears to provide reassurance and comfort. 

and genital touches are part of their play behaviour. In addition, S-type lip touches during normal situations, despite there being no relationship between this and touches for reassurance but as a playful behaviour. less U-type and S-type lip touches when the mahouts pulled their ears than when they did not. Mahouts usually pulled the ears of their elephants to direct them when walking and it is possible that by doing so, mahouts affected the activity of these elephants, resulting in elephants interacting less frequently with others while walking than during other situations, such as during feeding or bathing. involving interactions with the mahouts than those involving no such interaction. to compare, the frequency of U-type genital touches was not significantly different 
472 the mahouts. These results may indicate that U-type genital touches were not as

473 greatly affected by interactions with the mahouts as U-type and S-type lip touches.

474 However, additional systematic studies are required to better understand the relationship between elephants and their mahouts.

In addition, we investigated whether the touches were related to aggression touches, and the elephants also rarely displayed threatening postures during these touches. In contrast, the elephants exhibited aggressive behaviour more frequently before and after S-type lip touches, during which the actors typically adopted threatening postures. These findings support the results of the first analysis that investigated the relationship between U-type touches and the proximity index and may suggest that S-type lip touching is a more aggressive behaviour than U-type touching. Garaï (1992) reported that mouth touching, which includes touches with complex trunk twisting, was often observed in pairs of captive Asian elephants that showed frequent aggressive interactions and suggested that this may reduce aggressive motivation. Because the actors of S-type lip touches usually showed threatening postures, it might be difficult to consider this as appeasement 
490 touches in our study were associated with aggressive behaviour. It was

491 occasionally difficult to observe whether the elephants were touching the other

492 elephants inside or around the mouth as the actor's trunk tip was hidden by the

493 recipient's trunk. Thus, it is possible that the S-type lip touch in the present study

494 and the mouth touch with twisted trunk in Garaï's study refer to the same

495 behaviour.

As shown in Fig. 4, the likelihood of S-type lip touches escalating to

aggressive behaviour was not very high. Furthermore, this behaviour was never

observed in neonates, which are much smaller and weaker than the others. Thus,

we may suggest that female Asian elephants change their trunk shape during lip

touching, a frequently observed affiliative interaction, to show dominance both

visually and tactually. In this study, the subadults received S-type lip touches more

frequently than the adults, further supporting this interpretation, as two of the

three subadults were the newest members of the group and so may have needed to

504 find their places in the dominance hierarchy. 
508 individuals, but then develops into aggressive behaviour among adults. Similar

509 behavioural changes as a consequence of maturation are observed in other species;

510 for example, 'chase' and 'kick' behaviours in primates (Nishida et al. 2010; Cordoni

$511 \&$ Palagi 2011). There are few studies on the change in these behaviours from the

512 development viewpoint, though Nishida (2003) revealed that in wild chimpanzees

513 the reaction of recipients to such behaviours change depending on the actors' age.

515 depending on the age classes of the pairs. We found that the pairs that included

516 neonates used U-type genital touches more frequently than the pairs without

517 neonates. Previous studies on genital touches in Asian elephants have mainly

518 focused on reproductive behaviour (Meyer et al. 2008; Slade-Cain et al. 2008).

519 However, our results suggest that U-type genital touches may have an additional

520 function unrelated to reproductive behaviour. Elders touched the genitals of

521 neonates more frequently than neonates touched the genitals of the elders.

522 Therefore, it is possible that this behaviour was performed to assess the health of

523 the neonates while demonstrating affiliative relationships, as some previous

524 studies have suggested for both Asian and African elephants (Sukumar 2003; Moss

525 et al. 2011). 
527 affiliative interactions and disturbance, possibly for reassurance. Both touches

528 were observed frequently, as noted in previous studies (Garaï 1992; Makecha et al.

529 2012). Therefore, we recommend that more research is conducted on this topic,

530 because it might be possible that U-type touches in Asian elephants are 531 comparable with social grooming in primates or flipper rubbing in dolphins

532 (Nakamura \& Sakai 2013) as female Asian elephants also appear to use these touches as indicators of affiliative relationships. We did not focus on the functions

534 of these touch types from the viewpoint of chemical communication. Sexual maturation or dominance rank may be related to touch type; however, we were unable to obtain this information on our subjects. Therefore, it is also possible that each trunk touch type has additional functions, such as individual recognition or investigation of food, which requires further research.

S-type lip touches were observed in agonistic interactions and appeared to

540 be related to dominant behaviour. Animals often threaten opponents using visual

541 displays or vocalisations (Deag 1977; Randall 2001), and animals occasionally

542 place a part of their body over an opponent's body, such as mounting, to show

543 dominance (Maslow 1936; Goodwin et al. 1997). Both Asian and African elephants 
544 place their head over another elephant's head or back to show dominance (Olson

545 2004; Moss et al. 2011). However, in the case of S-type lip touches, the actors touch

546 the lips of recipients and do not put their weight on the bodies of recipients. Thus,

547 this behaviour appears to be intermediate between a visual threat display and

548 physical dominance behaviour and may be used as an initial step in an agonistic

549 interaction, -similar examples of which are rare in other mammals. Because trunk

550 touching does not hurt the recipient, it may also be possible for young individuals

551 to use S-type lip touches as one of their play behaviours. During play, it is common

552 to act out dominant or submissive roles, and thus it is reasonable to assume that

553 Asian elephants may use S-type lip touches as one of their play behaviours.

554 However, we need to collect more data and perform more detailed analyses to understand the reason for these elephants exhibiting this behaviour.

Some previous studies have reported the laterality of elephant trunks

557 (Martin \& Niemitz 2003; Haakonsson \& Semple 2009). For example, Martin and

Niemitz (2003) reported that wild Asian elephants have a side preference for

559 twisting their trunk when they grab grasses, and Haakonsson and Semple (2009) 
562 be related to the brain hemisphere. In the present study, we did not consider the

563 side to which the subjects twisted their trunks during S-type touches. However, it

564 is possible that the elephants also have a side preference for these touches, which

565 is related to their side preference during feeding.

The present study had several limitations. Our subjects were born in captivity and had lived and worked with their mahouts since they were young.

568 During our observations, the mahouts usually stayed around their elephants, and we found that interactions with the mahouts influenced the social behaviours of these elephants to some extent. Furthermore, it should be noted that the mere existence of mahouts and/or the relationship with them, may affect the social behaviour of the elephants, most of whom do not have as much social experience as wild elephants. Therefore, we need to confirm these results in wild Asian elephants to understand Asian elephant societies. touching in social relationships between Asian elephants, we demonstrated a novel social ability of this species that will assist in understanding relationships between individuals and their societies. 
582 (NRCT, Thailand) for allowing us to perform this study. We appreciate our research

583 collaborator, Dr Wanchai Tunwattana, a project manager of Elephant Kingdom

584 Project, Zoological Parks Organization. We thank Mr Alex Godfrey and Mr Jack

585 Chakkrapong, ex- and present Project Manager of the Surin Project, Save

586 Elephant Foundation, for granting permission to conduct our research with the

587 Surin Project. We would also like to thank all the staff and mahouts of the Surin

588 Project for their cooperation. We thank Dr Fred Bercovitch for his valuable

589 comments. This study was supported by grant-in-aid for Japan Society for the

590 Promotion of Science (JSPS) fellows (\#245462), and ITP-HOPE and AS-HOPE

591

programmes from JSPS.

592

593 
REFERENCES Akaike H. 1974. A new look at the statistical model identification.

Altmann J. 1974. Observational study of behaviour: Sampling methods. Behaviour. 49:227-267.

Cordoni G, Palagi E. 2011. Ontogenetic trajectories of chimpanzee social play: Similarities with humans. PloS One. 6:e27344.

600

Deag JM. 1977. Aggression and submission in monkey societies. Anim Behav. 25:

601 $465-474$.

de Silva S. 2010. Acoustic communication in the Asian elephant, Elephas maximus maximus. Behaviour. 147:825-852. $57: 121-131$.

Dunbar RI. 2010. The social role of touch in humans and primates: Behavioural function and neurobiological mechanisms. Neurosci Biobehav Rev. 34:260268. 

of tame Asiatic elephant (Elephas maximus Linn). Proc Indian Acad Sci. 93:225-233.

614 Garaï ME. 1992. Special relationships between female Asian elephants (Elephas maximus) in zoological gardens. Ethology. 90:187-205.

616 Goodwin D, Bradshaw JWS, Wickens SM. 1997. Paedomorphosis affects agonistic visual signals of domestic dogs. Anim Behav. 53:297-304.

618 Haakonsson JE, Semple S. 2009. Lateralisation of trunk movements in captive Asian elephants (Elephas maximus). Laterality. 144:413-422.

Hertenstein MJ, Verkamp JM, Kerestes AM, Holmes RM. 2006. The communicative functions of touch in humans, nonhuman primates, and rats: A review and synthesis of the empirical research. Genet Soc Gen Psychol Monogr. 132:5-94.

624 Hurlbert SH. 1984. Pseudoreplication and the design of ecological field experiments. Ecol Monogr. 54:187-211.

Kasper C, Voelkl B. 2009. A social network analysis of primate groups. Primates. 50:343-356. 
630 Langbauer WR Jr. 2000. Elephant communication. Zoo Biol. 19:425-445.

631 Makecha R, Fad O, Kuczaj SA. 2012. The role of touch in the social interactions of Asian elephants (Elephas maximus). Int J Comp Psychol. 25:60-82.

Martin F, Niemitz C. 2003. "Right-trunkers" and "left-trunkers": side preferences of trunk movements in wild Asian elephants (Elephas maximus). Int J Comp Psychol. 117:371-379.

Martin P, Bateson P. 1993. Measuring behaviour: An introductory guide. dominance in the social and sexual behaviour of infra-human primates: III. A Psychol. 48:310-338.

McCowan B, Anderson K, Heagarty A, Cameron A. 2008. Utility of social network analysis for primate behavioural management and well-being. Appl Anim Behav Sci. 109:396-405.

McNeill D. 1992. Hand and mind: What gestures reveal about thought. Chicago: University of Chicago Press. 
Anim Behav. 76:163-174.

649 Moss CJ. 1988. Elephant memories: Thirteen years in the life of an elephant family.

$650 \quad$ New York: William Morrow and Co. Inc.

651 Moss CJ, Croze H, Lee PC, editors. 2011. The Amboseli elephants: A long-term

652 perspective on a long-lived mammal. Chicago: University of Chicago Press.

653 Nair S, Balakrishnan R, Seelamantula CS, Sukumar R. 2009. Vocalizations of wild Asian elephants (Elephas maximus): structural classification and social context. J Acoust Soc Am. 126:2768-2778.

656 Nakamura M, Sakai M. 2013. Social touch in apes and dolphins. In: Yamagiwa J, Karczmarski L, editors. Primates and cetaceans: Field research and conservation of complex mammalian societies. Tokyo: Springer Japan; p. $355-383$.

660

Nishida T. 2003. Harassment of mature female chimpanzees by young males in the 661 Mahale Mountains. Int J Primatol. 24:503-514.

662

Nishida T, Zamma K, Matsusaka T, Inaba A, McGrew WC. 2010. Chimpanzee 663 behaviour in the wild. An audio-visual encyclopaedia. Tokyo: Springer Japan.

664 O'Connell-Rodwell CE. 2007. Keeping an "ear" to the ground: seismic 665 communication in elephants. Physiology. 22:287-294. 
666 Olson D. 2004. Elephant husbandry resource. Lawrence (KS): Allen Press.

667 Onodera S, Hicks TP. 1999. Review: Evolution of the motor system: Why the elephant's trunk works like a human's hand. Neuroscientist. 5:217-226.

669 Payne KB, Langbauer WR Jr, Thomas EM. 1986. Infrasonic calls of the Asian elephant (Elephas maximus). Behav Ecol Sociobiol. 18:297-301.

671

Plotnik JM, de Waal FBM. 2014. Asian elephants (Elephas maximus) reassure

672 others in distress. PeerJ. 2:e278.

673

Polthanee A, Promkhambut A. 2014. Impact of climate change on rice-based cropping systems and farmers' adaptation strategies in northeast Thailand. Asian J Crop Sci. 6:262-272.

676

Poole JH, Moss CJ. 2008. Elephant sociality and complexity: the scientific evidence, In: Wemmer C, Christen CA, editors. Elephants and ethics: towards a 98.

Randall JA. 2001. Evolution and function of drumming as communication in mammals. Am Zool. 41:1143-1156. 
Rasmussen LEL, Krishnamurthy V. 2000. How chemical signals integrate Asian elephant society: The known and the unknown. Zoo Biol. 19:405-423.

687

Sakai M, Hishii T, Takeda S, Kohshima S. 2006. Flipper rubbing behaviours in 688 wild bottlenose dolphins (Tursiops aduncus). Mar Mam Sci. 22:966-978.

Schel AM, Rawlings B, Claidiere N, Wilke C, Wathan J, Richardson J, Pearson S, Herrelko ES, Whiten A, Slocombe K. 2013. Network analysis of social 691 changes in a captive chimpanzee community following the successful integration of two adult groups. Am J Primatol. 75:254-266.

Slade BE, Schulte BA, Rasmussen LEL. 2003. Oestrous state dynamics in chemical communication by captive female Asian elephants. Anim Behav. 65:813-819.

Slade-Cain BE, Rasmussen LEL, Schulte BA. 2008. Estrous state influences on investigative, aggressive, and tail flicking behaviour in captive female Asian elephants. Zoo Biol. 27:167-180.

Spruijt BM, van Hooff JA, Gispen WH. 1992. Ethology and neurobiology of grooming behaviour. Physiol Rev. 72:825-852. 
conservation. New York: Oxford University Press.

703 Tamaki N, Morisaka T, Taki M. 2006. Does body contact contribute towards repairing relationships? The association between flipper-rubbing and aggressive behaviour in captive bottlenose dolphins. Behav Prosses. 73:209215.

707

Thitaram C, Chansitthiwet S, Pongsopawijit P, Brown JL, Wongkalasin W, Daram Use of genital inspection and female urine tests to detect oestrus in captive Asian elephants. Anim Reprod Sci. 115:267-278.

711 Vidya TNC, Sukumar R. 2005. Social and reproductive behaviour in elephants. Curr Sci. 89:1200-1207.

713

Wittemyer G, Douglas-Hamilton I, Getz WM. 2005. The socioecology of elephants: analysis of the processes creating multitiered social structures. Anim Behav. 69:1357-1371. 
720

\section{APPENDICES}

Table S1.

Reasons for excitement

\begin{tabular}{|c|c|c|}
\hline Reason & Description & $\begin{array}{l}\text { No. of events } \\
\text { (with and without } \\
\text { mahout } \\
\text { interactions) }\end{array}$ \\
\hline Disturbance & $\begin{array}{l}\text { Elephants were disturbed by the sounds of } \\
\text { cars or firecrackers, other species such as } \\
\text { dogs or buffaloes and other elephants' } \\
\text { vocalisations }\end{array}$ & $\begin{array}{c}234 \\
(87,147)\end{array}$ \\
\hline Play & $\begin{array}{l}\text { Elephants became excited during bathing or } \\
\text { dusting or before feeding }\end{array}$ & $\begin{array}{c}64 \\
(20,44) \\
\end{array}$ \\
\hline $\begin{array}{l}\text { Mahout's } \\
\text { interaction }\end{array}$ & $\begin{array}{l}\text { Elephants reacted to interactions with their } \\
\text { mahouts }\end{array}$ & $\begin{array}{c}49 \\
(49,0)\end{array}$ \\
\hline Unknown & $\begin{array}{l}\text { We were unable to identify the reason why } \\
\text { elephants became excited. }\end{array}$ & $\begin{array}{c}288 \\
(93,195)\end{array}$ \\
\hline
\end{tabular}

721 
Table S2.

723 The social behaviours that occurred before or after touches. The percentages were calculated using the fomula $\mathrm{N}_{\text {before or after }} / \mathrm{N}_{\text {touch }} \times$ 100 (where $\mathrm{N}_{\text {before or after }}=$ the number of times that behaviouroccurred in each category before or after the touches and $\mathrm{N}_{\text {touch }}=$ the total number of touch events). * indicates that the rates were significantly different (GLMER followed by Tukey's test). We did not perform statistical analyses for 'unknown'.

\begin{tabular}{|c|c|c|c|c|c|c|}
\hline \multirow{2}{*}{ Timing } & \multirow{2}{*}{ Touch } & \multicolumn{5}{|c|}{ Categories of behaviours before or after touch (\%) } \\
\hline & & Movement & Play & Aggression & Touch or smell & Unknown \\
\hline \multirow{3}{*}{ Before } & U-type $\operatorname{lip}(N=1444)$ & 45.27 & 2.2 & 0.17 & 51.07 & 1.5 \\
\hline & $\begin{array}{l}\text { U-type genital }(N= \\
807)\end{array}$ & 41.9 & 1.9 & $0.1]_{-}^{*}$ & $54.2\rfloor *$ & 1.9 \\
\hline & S-type lip $(N=193)$ & 35.2 & 7.8 & 5.2 & 51.2 & 0.6 \\
\hline \multirow{3}{*}{ After } & U-type $\operatorname{lip}(N=1444)$ & 40.27 & 2.8 & 0.27 & 52.6 & 4.3 \\
\hline & $\begin{array}{l}\text { U-type genital }(N= \\
807)\end{array}$ & 40.5 & 1.6 & $0.0]^{*}$ & 52.3 & 5.6 \\
\hline & S-type lip $(N=193)$ & 30.6 & 5.7 & 9.3 & 50.3 & 4.1 \\
\hline
\end{tabular}


Table 1.

Subjects included in this study. The individuals with bold characters were the focal animals for this study. o indicates that the individual stayed in the group during the particular period while $\times$ indicates that they did not stay in the group during that particular period. * means that the individual joined or left the group in the middle of the period.

\begin{tabular}{|c|c|c|c|c|c|c|c|}
\hline $\begin{array}{c}\text { Name } \\
\text { (Abbreviations) }\end{array}$ & Sex & $\begin{array}{c}\text { Age } \\
\text { (years) }\end{array}$ & Age class & Relationship & Period1 & Period2 & $\begin{array}{l}\text { Focal time } \\
(\mathrm{hr})\end{array}$ \\
\hline Kaem sean (KS) & $\mathrm{F}$ & 26 & Adult & & o & o & 25.0 \\
\hline Fah sai (FS) & $\mathrm{F}$ & 23 & Adult & & o & o & 28.4 \\
\hline Mem (ME) & $\mathrm{F}$ & 20 & Adult & & o & o & 30.2 \\
\hline Euang loaung (EL) & $\mathrm{F}$ & 18 & Adult & & o & o & 26.2 \\
\hline Sai faa (SF) & $\mathrm{F}$ & 15 & Subadult & & o & o & 25.2 \\
\hline Kanoon (KN) & $\mathrm{F}$ & 13 & Subadult & & o & o & 24.7 \\
\hline Gem (GE) & $\mathrm{F}$ & 11 & Subadult & & o & o & 27.4 \\
\hline Nong nung (NO) & $\mathrm{F}$ & 9 & Juvenile & & 0 & o & 28.4 \\
\hline Nung ning (NU) & $\mathrm{F}$ & 9 & Juvenile & & o & o & 28.0 \\
\hline Teng mo (TM) & $\mathrm{F}$ & 7 & Juvenile & & o & o & 28.4 \\
\hline Nopa gao & M & 1 & Neonate & Kaem sean's son & o & $\times$ & - \\
\hline Ploy & $\mathrm{F}$ & 17 & Adult & & $\times$ & o & - \\
\hline Khwan & $\mathrm{F}$ & 1 & Neonate & Ploy's daughter & $\times$ & o & - \\
\hline Thong deng & $\mathrm{F}$ & 19 & Adult & & * & $\times$ & - \\
\hline Soi thong & $\mathrm{F}$ & 0.67 & Neonate & Thong deng's daughter & * & $\times$ & - \\
\hline Tuk & $\mathrm{F}$ & 10 & Juvenile & & * & $\times$ & - \\
\hline Kham koon & $\mathrm{F}$ & 5 & Juvenile & & $\times$ & $*$ & - \\
\hline
\end{tabular}


Table 2 .

Ethogram of social behaviours.

\begin{tabular}{|c|c|}
\hline Behavioiur & Definition \\
\hline \multicolumn{2}{|l|}{ MOVEMENT } \\
\hline Approach & Move towards other individual such that they can touch each other (reach distance) \\
\hline Leave & Move away from the reach distance of other individual \\
\hline Follow & Walk behind other individual while maintaining the reach distance \\
\hline \multicolumn{2}{|l|}{ TOUCH OR SMELL } \\
\hline Touch & $\begin{array}{l}\text { Touch other elephant's body (lip, genitals, body, head, mouth, ear, leg, tail, trunk, trunk tip) with } \\
\text { the trunk tip }\end{array}$ \\
\hline Touch with other body parts & Touch other elephant's body with other body parts, such as body, tail, leg \\
\hline Trunk toward & Move trunk towards other elephant \\
\hline \multicolumn{2}{|l|}{ AGGRESSION } \\
\hline Head butt & Thump head against other elephant's head or body \\
\hline Trunk hit & Slap other elephant's head or body with trunk \\
\hline Kick & Kick other elephant's body with foreleg or hind leg \\
\hline Trunk/head over head & Put trunk or head on other elephant's head \\
\hline $\begin{array}{l}\text { Trunk/head over } \\
\text { back-aggressive }\end{array}$ & Put trunk or head on other elephant's back when the recipient is standing \\
\hline Push-aggressive & Push other elephant's head with raised head \\
\hline Push with tush & Push other elephant's body with tush \\
\hline \multicolumn{2}{|l|}{ PLAY } \\
\hline Mount & Put forelegs on other elephant's body from behind or side \\
\hline Trunk/head over back -play & Put trunk or head on other elephant's back when the recipient is sitting \\
\hline Push-play & Push other elephant's head or body with head or body without raised head \\
\hline Rub & Rub head or body against other elephant's head or body \\
\hline \multicolumn{2}{|l|}{ VOCALISATION } \\
\hline Trunk smack & Hit ground with trunk outside and make sound \\
\hline Air burst & Blow air from trunk and make noise \\
\hline Other vocalisation & Rumble, growl, trumpet, squeak, chirp \\
\hline \multicolumn{2}{|l|}{ POSTURE } \\
\hline Threat posture & Raise head and extend ears towards opponent \\
\hline
\end{tabular}


Table 3.

738

Observed times and frequencies of touches in each focal animal.

\begin{tabular}{|c|c|c|c|c|c|c|c|c|c|}
\hline \multirow{2}{*}{$\begin{array}{c}\text { Focal } \\
\text { animal }\end{array}$} & \multicolumn{3}{|c|}{ U-type lip } & \multicolumn{3}{|c|}{ U-type genital } & \multicolumn{3}{|c|}{ S-type lip } \\
\hline & $\begin{array}{c}\mathrm{N} \\
\text { (times) }\end{array}$ & $\begin{array}{c}\text { Act } \\
\text { (times/hr) }\end{array}$ & $\begin{array}{c}\text { Receive } \\
\text { (times/hr) }\end{array}$ & $\begin{array}{c}\mathrm{N} \\
\text { (times) }\end{array}$ & $\begin{array}{c}\text { Act } \\
\text { (times/hr) }\end{array}$ & $\begin{array}{c}\text { Receive } \\
\text { (times/hr) }\end{array}$ & $\begin{array}{c}\mathrm{N} \\
\text { (times) }\end{array}$ & $\begin{array}{c}\text { Act } \\
\text { (times/hr) }\end{array}$ & $\begin{array}{c}\text { Receive } \\
\text { (times/hr) }\end{array}$ \\
\hline $\mathrm{KS}$ & 85 & 1.68 & 1.72 & 25 & 0.32 & 0.76 & 10 & 0.24 & 0.16 \\
\hline FS & 226 & 4.43 & 3.52 & 96 & 1.13 & 2.25 & 25 & 0.60 & 0.28 \\
\hline $\mathrm{ME}$ & 63 & 1.19 & 0.89 & 101 & 2.75 & 0.60 & 6 & 0.13 & 0.07 \\
\hline $\mathrm{EL}$ & 197 & 3.06 & 4.47 & 67 & 1.11 & 1.45 & 3 & 0.00 & 0.11 \\
\hline $\mathrm{SF}$ & 138 & 3.22 & 2.27 & 45 & 0.91 & 0.87 & 41 & 0.36 & 1.27 \\
\hline $\mathrm{KN}$ & 138 & 2.87 & 2.71 & 169 & 4.57 & 2.18 & 23 & 0.36 & 0.57 \\
\hline GE & 198 & 4.49 & 2.74 & 102 & 3.40 & 0.33 & 8 & 0.07 & 0.22 \\
\hline $\mathrm{NO}$ & 151 & 2.46 & 2.85 & 52 & 1.20 & 0.63 & 21 & 0.18 & 0.56 \\
\hline $\mathrm{NU}$ & 116 & 2.29 & 1.86 & 34 & 0.68 & 0.54 & 54 & 1.48 & 0.50 \\
\hline $\mathrm{TM}$ & 132 & 2.25 & 2.39 & 118 & 0.77 & 3.31 & 2 & 0.04 & 0.04 \\
\hline
\end{tabular}


739

740

741

742

743

744
Table 4

Observed touch frequencies for each pair. 'Other' shows the average frequency with which the animals other than the focal animals performed touches with the focal animal. The values that rank in the top $10 \%$ are highlighted.

(a) U-type lip

\begin{tabular}{|c|c|c|c|c|c|c|c|c|c|c|c|c|}
\hline & \multicolumn{11}{|c|}{ Recipient } \\
\hline & & $\mathrm{KS}$ & FS & $\mathrm{ME}$ & EL & $\mathrm{SF}$ & $\mathrm{KN}$ & GE & NO & $\mathrm{NU}$ & TM & Other \\
\hline \multirow{11}{*}{$\begin{array}{l}\text { 苍 } \\
\text { 䓵 }\end{array}$} & $\mathrm{KS}$ & & 0.31 & 0.02 & 0.25 & 0.11 & 0.42 & 0.16 & 0.14 & 0.02 & 0.06 & 0.10 \\
\hline & FS & 0.17 & & 0.16 & 1.63 & 0.20 & 0.21 & 0.07 & 1.50 & 0.18 & 0.11 & 0.03 \\
\hline & $\mathrm{ME}$ & 0.02 & 0.05 & & 0.16 & 0.23 & 0.22 & 0.05 & 0.21 & 0.00 & 0.04 & 0.14 \\
\hline & EL & 0.21 & 0.88 & 0.07 & & 1.13 & 0.02 & 0.08 & 0.21 & 0.18 & 0.11 & 0.05 \\
\hline & $\mathrm{SF}$ & 0.04 & 0.35 & 0.02 & 1.54 & & 0.07 & 0.10 & 0.19 & 0.33 & 0.08 & 0.26 \\
\hline & $\mathrm{KN}$ & 0.76 & 0.14 & 0.04 & 0.02 & 0.14 & & 0.08 & 0.08 & 0.10 & 0.31 & 0.23 \\
\hline & GE & 0.20 & 0.04 & 0.09 & 0.08 & 0.16 & 0.18 & & 0.16 & 0.04 & 2.67 & 0.01 \\
\hline & NO & 0.18 & 0.99 & 0.12 & 0.24 & 0.21 & 0.12 & 0.07 & & 0.27 & 0.07 & 0.01 \\
\hline & NU & 0.02 & 0.33 & 0.02 & 0.31 & 0.25 & 0.14 & 0.23 & 0.44 & & 0.45 & 0.00 \\
\hline & TM & 0.15 & 0.20 & 0.05 & 0.11 & 0.00 & 0.29 & 1.63 & 0.13 & 0.74 & & 0.00 \\
\hline & Other & 0.14 & 0.03 & 0.14 & 0.23 & 0.07 & 0.27 & 0.04 & 0.06 & 0.01 & 0.01 & \\
\hline
\end{tabular}

(b) U-type genital

\begin{tabular}{|c|c|c|c|c|c|c|c|c|c|c|c|c|}
\hline & \multicolumn{11}{|c|}{ Recipient } \\
\hline & & $\mathrm{KS}$ & FS & $\mathrm{ME}$ & $\mathrm{EL}$ & $\mathrm{SF}$ & $\mathrm{KN}$ & GE & NO & NU & TM & Other \\
\hline \multirow{2}{*}{ 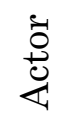 } & KS & & 0.02 & 0.00 & 0.04 & 0.02 & 0.32 & 0.02 & 0.00 & 0.02 & 0.00 & 0.02 \\
\hline & FS & 0.00 & & 0.00 & 0.44 & 0.04 & 0.02 & 0.05 & 0.48 & 0.04 & 0.02 & 0.00 \\
\hline
\end{tabular}




\begin{tabular}{|lllllllllllllll}
$\mathrm{ME}$ & 0.15 & 0.28 & & 0.09 & 0.14 & 0.31 & 0.02 & 0.03 & 0.07 & 0.07 & 0.55 \\
$\mathrm{EL}$ & 0.04 & 0.56 & 0.00 & & 0.29 & 0.02 & 0.02 & 0.02 & 0.04 & 0.00 & 0.08 \\
$\mathrm{SF}$ & 0.00 & 0.20 & 0.02 & 0.41 & & 0.11 & 0.04 & 0.02 & 0.08 & 0.00 & 0.14 \\
$\mathrm{KN}$ & 0.56 & 0.08 & 0.06 & 0.15 & 0.11 & & 0.12 & 0.16 & 0.14 & 0.24 & 0.98 \\
$\mathrm{GE}$ & 0.00 & 0.04 & 0.07 & 0.02 & 0.04 & 0.16 & & 0.04 & 0.04 & 2.98 & 0.01 \\
$\mathrm{NO}$ & 0.00 & 0.77 & 0.02 & 0.11 & 0.04 & 0.06 & 0.04 & & 0.04 & 0.04 & 0.05 \\
$\mathrm{NU}$ & 0.04 & 0.16 & 0.00 & 0.06 & 0.06 & 0.22 & 0.05 & 0.04 & & 0.05 & 0.01 \\
$\mathrm{TM}$ & 0.04 & 0.07 & 0.00 & 0.02 & 0.02 & 0.20 & 0.20 & 0.00 & 0.15 & & 0.01 \\
\hline
\end{tabular}

(c) S-type lip

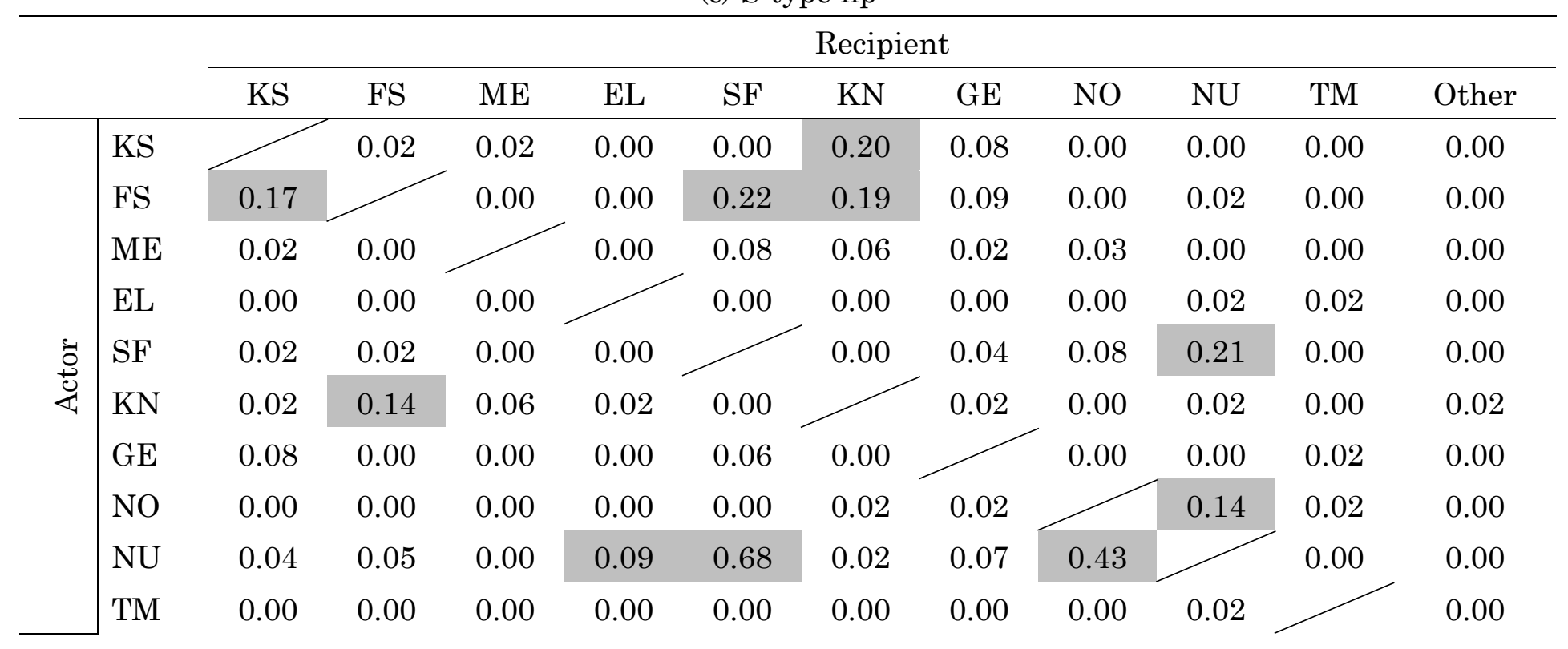


Table 5.

Statistical results of the generalised linear mixed-effect models followed by Tukey's test for the analyses of excited situations. $\mathrm{m}$ refers to situations with interactions by the mahouts. * indicates $P<0.05$ and ** indicates $P<0.01$.

\begin{tabular}{|c|c|c|c|c|c|c|c|c|c|}
\hline \multirow[b]{2}{*}{ (a) Excited or normal situations } & \multicolumn{3}{|c|}{ U-type lip } & \multicolumn{3}{|c|}{ U-type genitals } & \multicolumn{3}{|c|}{ S-type lip } \\
\hline & Coefficient & $z$ & $P$ & Coefficient & $z$ & $P$ & Coefficient & $z$ & $P$ \\
\hline $\operatorname{Normal}(\mathrm{m})$ vs. normal & $-0.90 \pm 0.14$ & -6.43 & $* *$ & $0.05 \pm 0.12$ & 0.42 & 0.98 & $-1.77 \pm 0.59$ & -3.02 & * \\
\hline $\operatorname{Normal}(m)$ vs. $\operatorname{excited}(m)$ & $-1.91 \pm 0.16$ & -11.67 & $* *$ & $-1.35 \pm 0.16$ & -8.54 & $* *$ & $-0.91 \pm 0.82$ & -1.11 & 0.66 \\
\hline $\operatorname{Normal}(\mathrm{m})$ vs. excited & $-2.21 \pm 0.15$ & -14.38 & $* *$ & $-1.33 \pm 0.15$ & -9.06 & $* *$ & $-2.03 \pm 0.66$ & -3.10 & * \\
\hline Normal vs. excited(m) & $-1.01 \pm 0.09$ & -10.64 & $* *$ & $-1.40 \pm 0.12$ & -11.78 & $* *$ & $0.86 \pm 0.58$ & 1.47 & 0.43 \\
\hline Normal vs. excited & $-1.31 \pm 0.08$ & -17.06 & $* *$ & $-1.38 \pm 0.11$ & -13.13 & $* *$ & $-0.26 \pm 0.31$ & 0.31 & 0.82 \\
\hline Excited(m) vs. excited & $-0.30 \pm 0.11$ & -2.63 & * & $0.02 \pm 0.15$ & 0.13 & 0.99 & $-1.12 \pm 0.65$ & -1.72 & 0.29 \\
\hline (b) Detailed situations & Coefficient & $z$ & $P$ & Coefficient & $z$ & $P$ & Coefficient & $z$ & $P$ \\
\hline $\operatorname{Normal}(m)$ vs normal & $-0.91 \pm 0.14$ & -6.48 & $* *$ & $0.09 \pm 0.12$ & 0.73 & 0.97 & $-1.75 \pm 0.59$ & -3.00 & * \\
\hline $\operatorname{Normal}(m)$ vs disturbance(m) & $-2.22 \pm 0.18$ & -12.69 & $* *$ & $-1.55 \pm 0.18$ & -8.49 & $* *$ & $-1.17 \pm 0.92$ & -1.27 & 0.78 \\
\hline $\operatorname{Normal}(\mathrm{m})$ vs disturbance & $-2.50 \pm 0.17$ & -14.33 & $* *$ & $-1.09 \pm 0.21$ & -5.19 & $* *$ & $-2.32 \pm 0.74$ & -3.15 & * \\
\hline $\operatorname{Normal}(m)$ vs play $(m)$ & $-1.96 \pm 0.22$ & -8.81 & $* *$ & $-1.31 \pm 0.25$ & -5.29 & $* *$ & $-1.61 \pm 0.92$ & -1.75 & 0.47 \\
\hline $\operatorname{Normal}(m)$ vs play & $-2.01 \pm 0.30$ & -6.66 & $* *$ & $-1.29 \pm 0.37$ & -3.46 & $* *$ & $-2.89 \pm 0.77$ & -3.74 & $* *$ \\
\hline Normal vs disturbance(m) & $-1.31 \pm 0.11$ & -11.65 & $* *$ & $-1.64 \pm 0.15$ & -10.98 & $* *$ & $0.59 \pm 0.71$ & 0.82 & 0.96 \\
\hline Normal vs disturbance & $-1.59 \pm 0.11$ & -14.26 & $* *$ & $-1.18 \pm 0.18$ & -6.48 & $* *$ & $-0.56 \pm 0.46$ & -1.23 & 0.80 \\
\hline Normal vs play(m) & $-1.05 \pm 0.18$ & -5.96 & $* *$ & $-1.40 \pm 0.22$ & -6.31 & $* *$ & $0.15 \pm 0.71$ & 0.21 & 0.99 \\
\hline Normal vs play & $-1.10 \pm 0.27$ & -4.06 & $* *$ & $-1.38 \pm 0.36$ & -3.84 & $* *$ & $-1.13 \pm 0.51$ & -2.21 & 0.21 \\
\hline Disturbance $(\mathrm{m})$ vs disturbance & $-0.27 \pm 0.15$ & -1.82 & 0.42 & $0.46 \pm 0.23$ & 2.02 & 0.30 & $-1.15 \pm 0.84$ & -1.37 & 0.72 \\
\hline Disturbance(m) vs play(m) & $0.26 \pm 0.20$ & 1.26 & 0.78 & $0.24 \pm 0.26$ & 0.95 & 0.92 & $-0.44 \pm 1.00$ & -0.44 & 0.99 \\
\hline Disturbance (m) vs play & $0.21 \pm 0.29$ & 0.73 & 0.97 & $0.26 \pm 0.38$ & 0.69 & 0.98 & $-1.72 \pm 0.87$ & -1.97 & 0.33 \\
\hline Disturbance vs play(m) & $0.53 \pm 0.20$ & 2.62 & 0.08 & $-0.22 \pm 0.28$ & -0.77 & 0.97 & $0.71 \pm 0.84$ & 0.85 & 0.95 \\
\hline
\end{tabular}


Disturbance vs play

$0.49 \pm 0.29$

1.69

0.50

$-0.20 \pm 0.40$

$-0.49$

0.99

$-0.57 \pm 0.68$

$-0.85$ 
751 Fig. 1. - Examples of (a) U-type lip and (b) S-type lip touches.

752 Fig. 2. - Mean frequency of touches to each body part. The values are individual

753 means \pm SD.

754 Fig. 3. - Relationships between the percentage of time in proximity to an

755 individual and the number of times (a) U-type lip, (b) U-type genital and (c) S-type

756 lip touches were performed.

757 Fig. 4. - Proportion of times that play or aggressive behaviours occurred (a)

758 before and (b) after the touches.

759 Fig. 5. - Proportion of times that play or aggressive behaviours occurred (a)

760 before and (b) after S-type touches between pairs with and without young.

761 Fig. 6. - Relationship between the number of times U-type lip and U-type genital touches occurred in pairs with or without neonates. 
Fig. 1

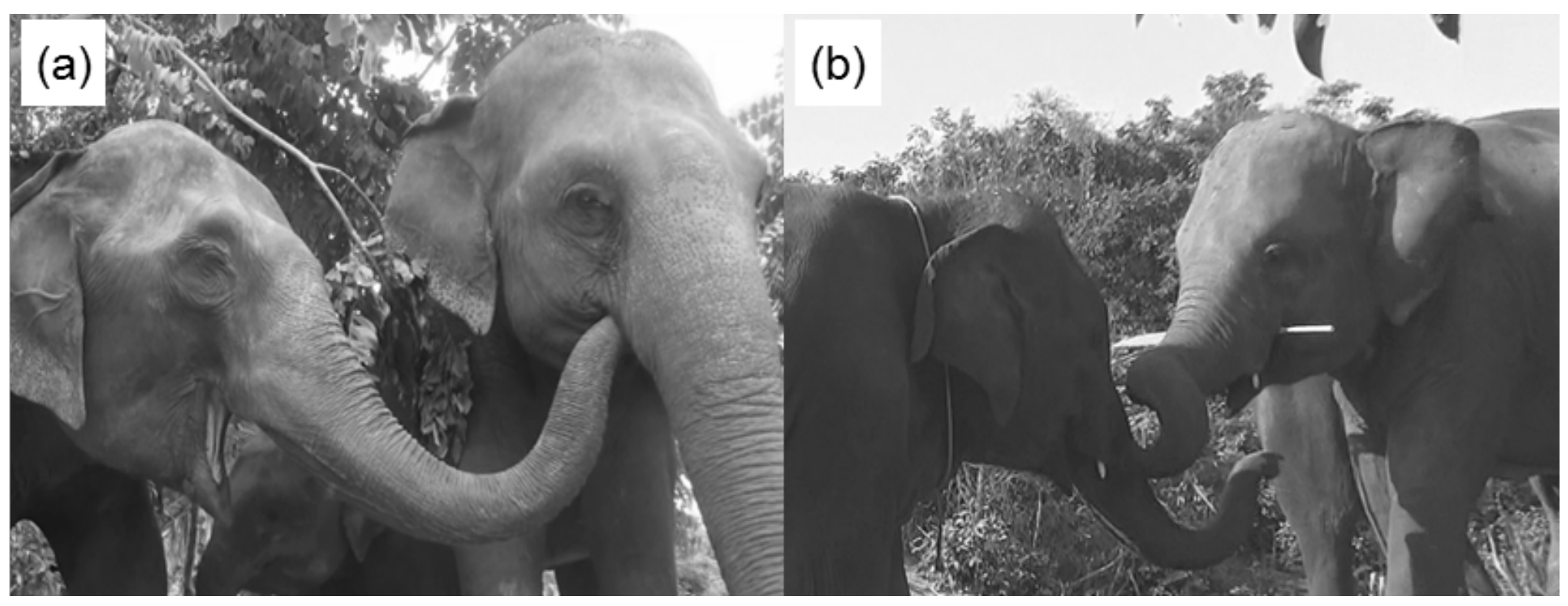


Fig. 2

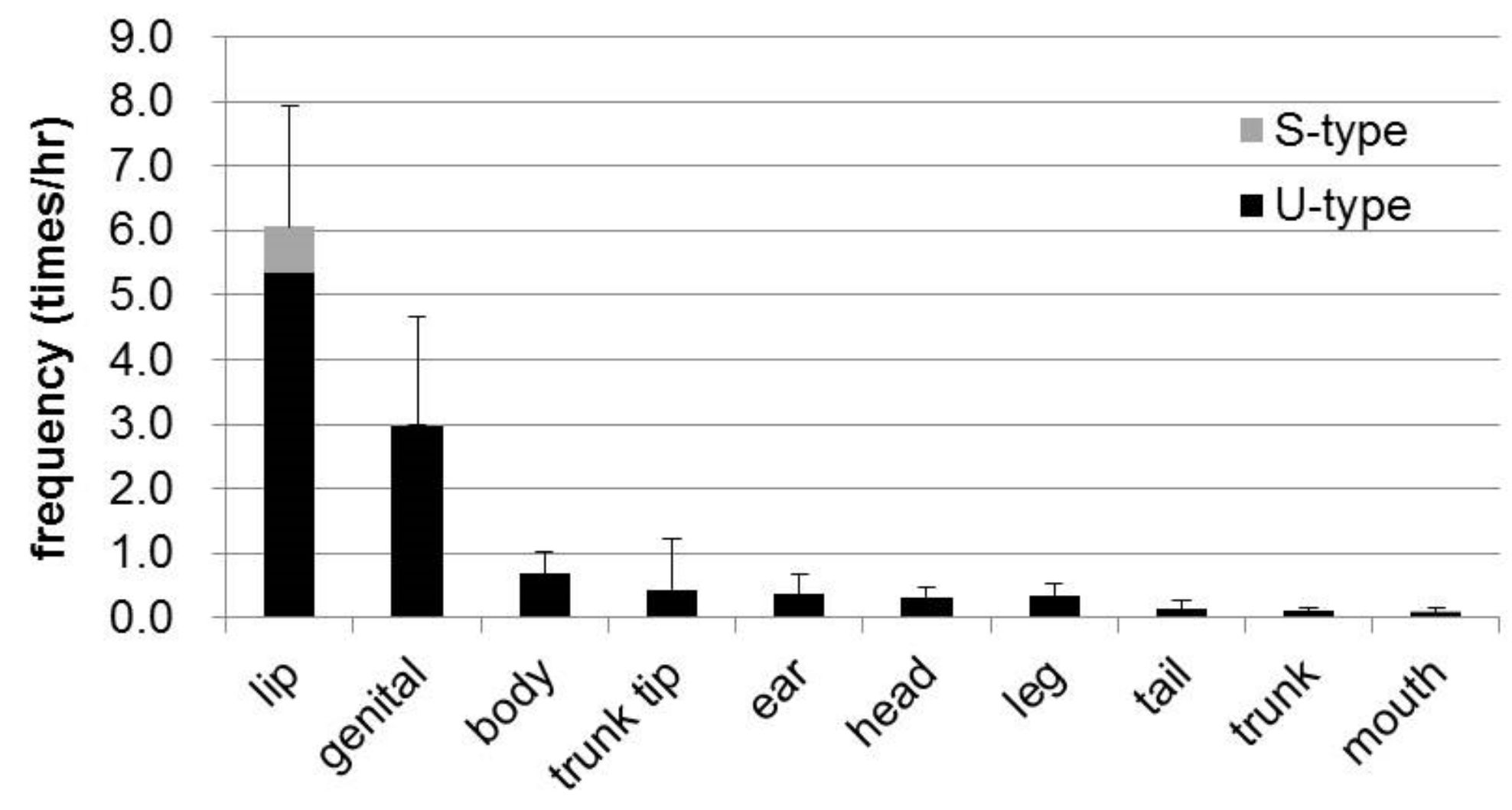


Fig. 3
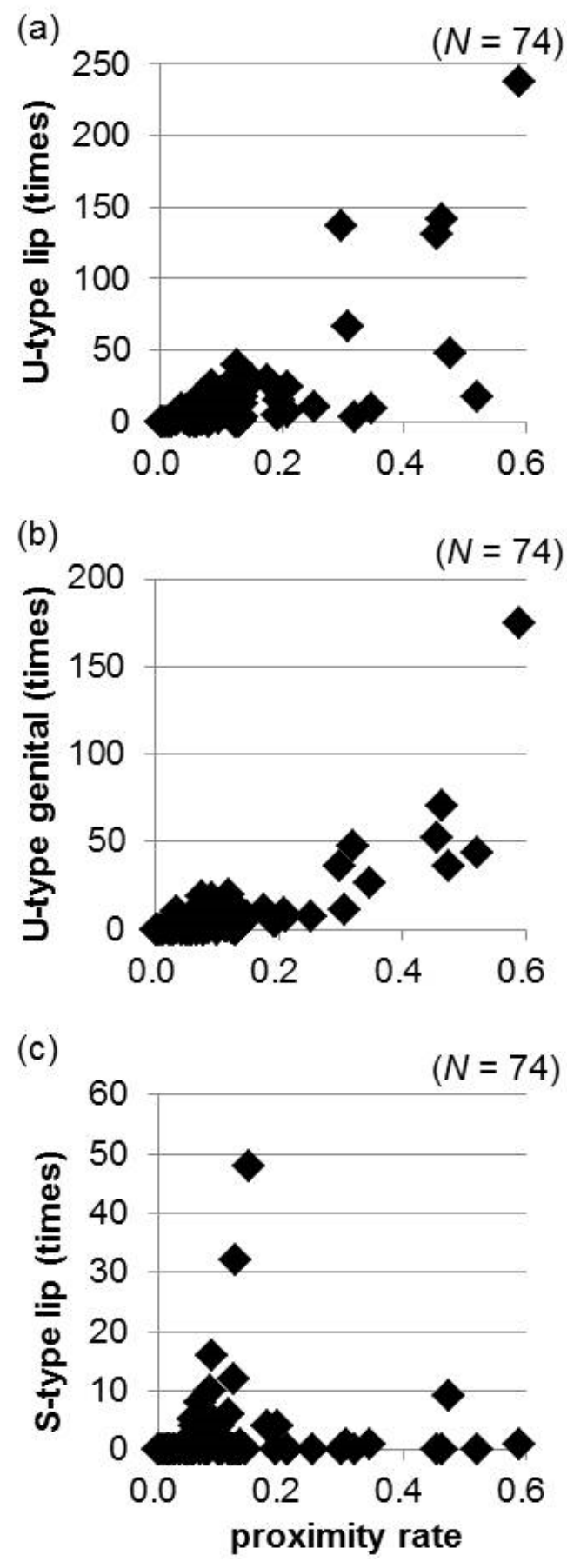
Fig. 4
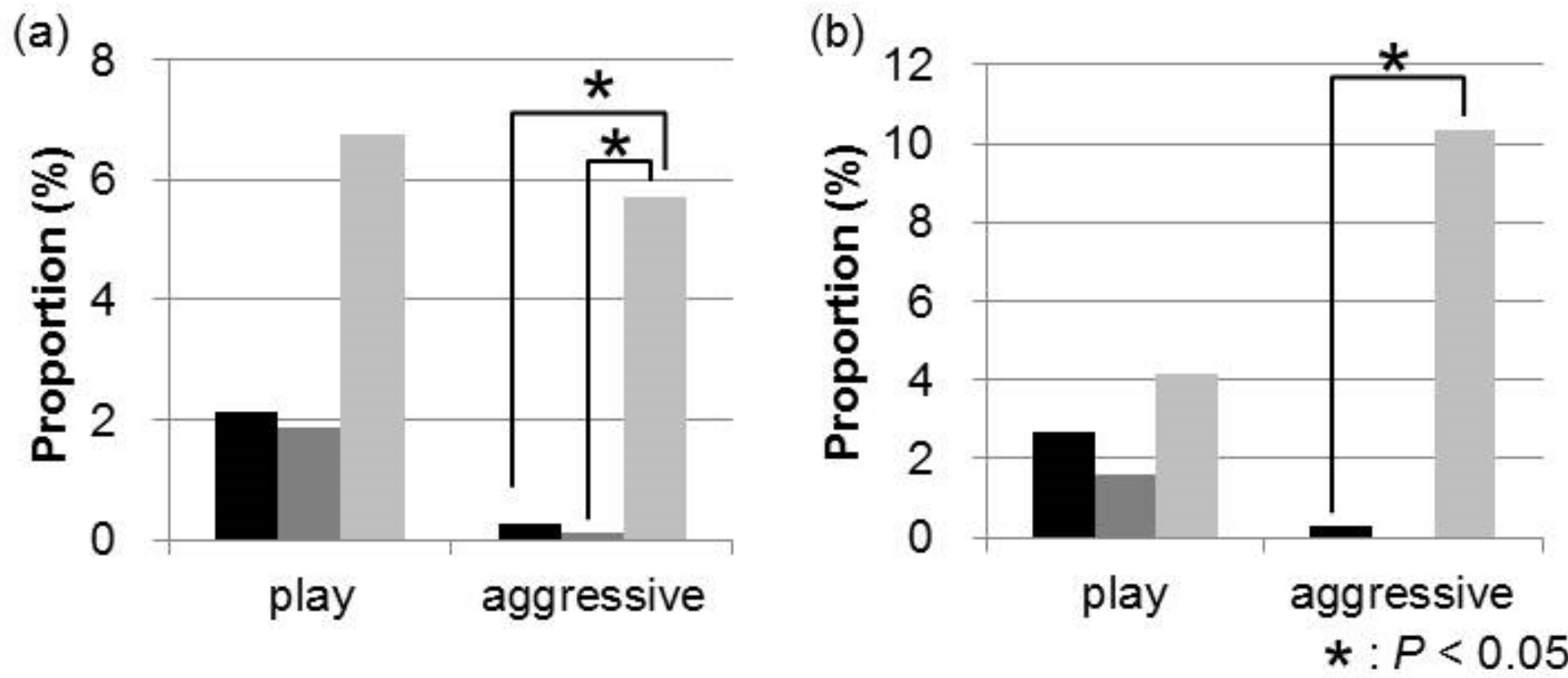

U-type lip $(N=1444) \square$ U-type genital $(N=807) \square$ S-type lip $(N=193)$ 
Fig. 5
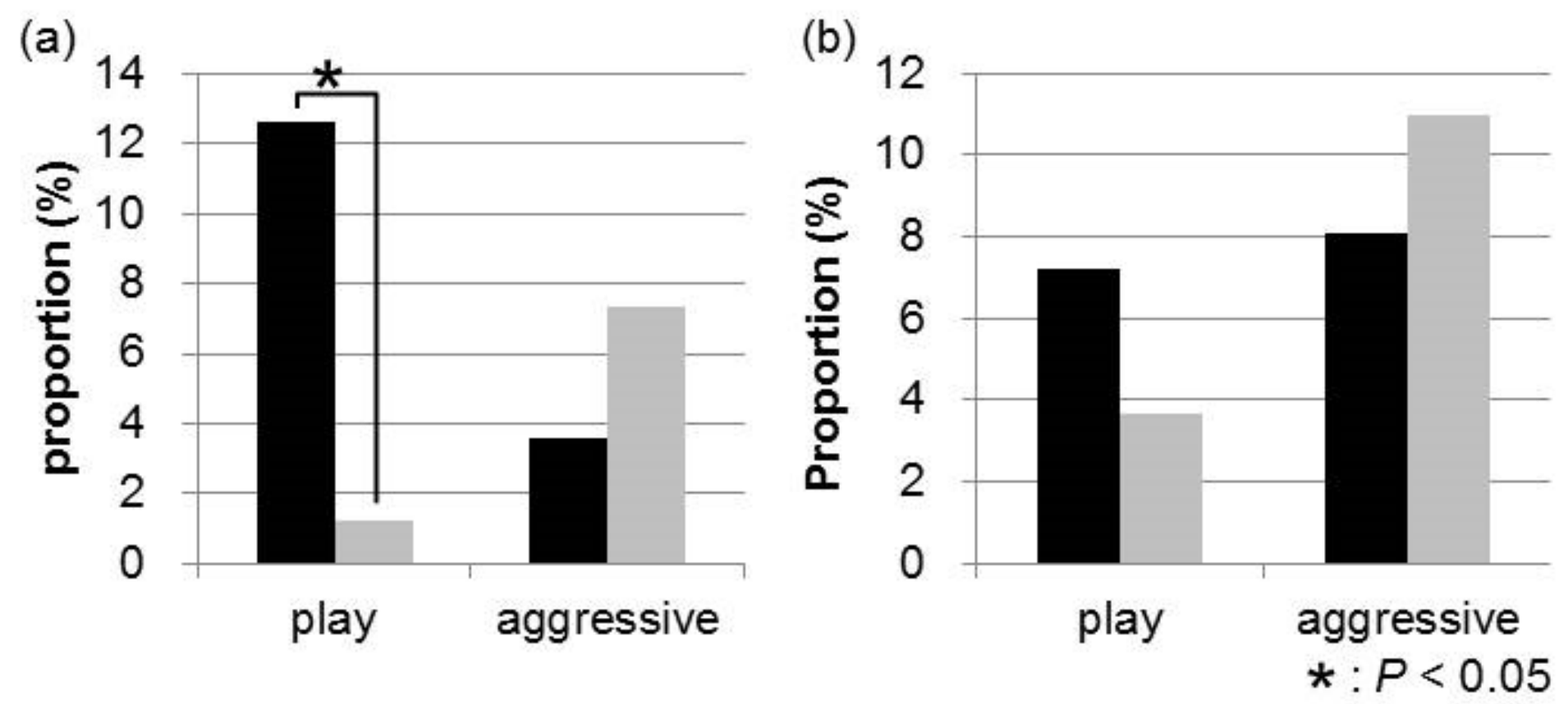

with young $(N=111)$ without young $(N=82)$ 
Fig. 6

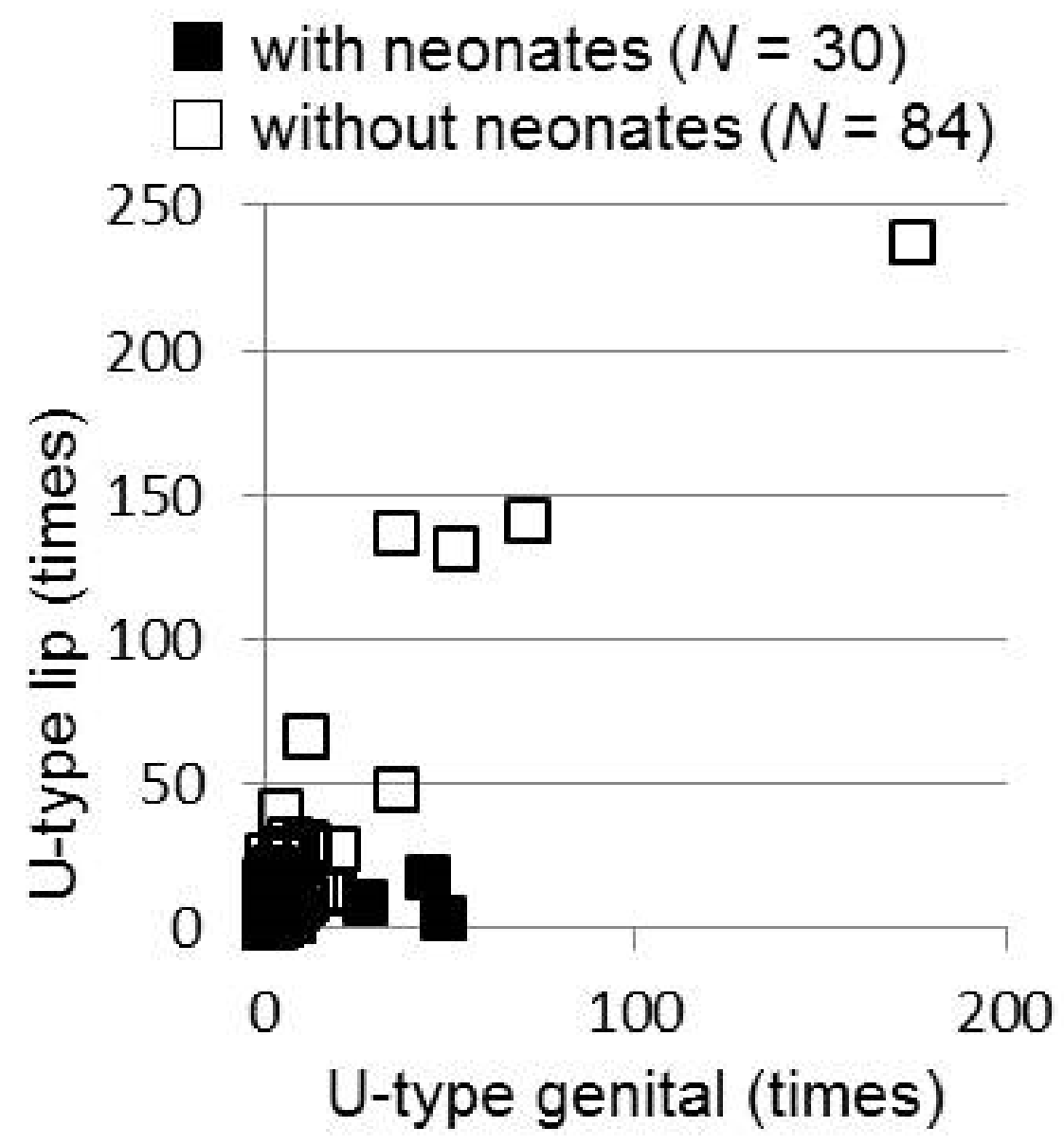

